University of Rhode Island

DigitalCommons@URI

Open Access Dissertations

1979

\title{
The Modification of Impulsive Behavior with Learning Disabled Boys: A Verbal Self-Instructional Approach
}

Vicki Lynn Moss

University of Rhode Island

Follow this and additional works at: https://digitalcommons.uri.edu/oa_diss

\section{Recommended Citation}

Moss, Vicki Lynn, "The Modification of Impulsive Behavior with Learning Disabled Boys: A Verbal SelfInstructional Approach" (1979). Open Access Dissertations. Paper 978.

https://digitalcommons.uri.edu/oa_diss/978

This Dissertation is brought to you for free and open access by DigitalCommons@URI. It has been accepted for inclusion in Open Access Dissertations by an authorized administrator of DigitalCommons@URI. For more information, please contact digitalcommons-group@uri.edu. 
THE MODIFICATION OF IMPULSIVE BEHAVIOR WITH LEARNING DISABLED BOYS: A VERBAL SELF-INSTRUCTIONAL APPROACH BY VICKI LYNN MOSS

A DISSERTATION SUBMITTED IN PARTIAL FULFILLMENT OF THE REQUIREMENTS FOR THE DEGREE OF DOCTOR OF PHILOSOPHY

IN

PSYCHOLOGY

UNIVERSITY OF RHODE ISLAND

1979 


\section{ABSTRACT}

Seventy-six impulsive, learning disabled boys were tutored individually for five half-hour sessions. Experimental subjects were trained in verbal self-instructional techniques, which taught them how to think aloud and which necessitated good attention to task. Control subjects were tutored in a more traditional manner, with tutors receiving no specific instructions. Half of each group worked with academic tasks, while the other half worked with copying, visual-perceptua 1, and other non-academic tasks. Results indicated that all groups improved significantly from pre- to posttesting on measures of impulsivity (latency and accuracy), classroom behavior and performance, and achievement. None of the Training by Trials, nor Training by Trials by Task interactions was significant. Implications for future research and educational practice were discussed. 


\section{ACKNOWLEDGEMENTS}

The completion of this dissertation marks the end of an era for me. In the ten years since I first began graduate study, I have had the pleasure of interfacing with many special and talented individuals, each of whom contributed a unique piece to my professional identity. While the list is far too long to be included here, there are a few who stand out in memory.

Dr. Gilbert Trachtman, Director of the School Psychology training program at New York University, is an exceptional teacher, psychologist, and mentor. His professionalism and high ethical standards continue to serve as an inspiration to me. During my internship year at Catholic Charities Guidance Clinics in New York, I had the pleasure of knowing and being supervised by $\mathrm{Dr}$. Monroe Gottesgen. With his encouragement and outstanding skill as a diagnostician, therapist, and teacher, I successfully made the transition from student to professional.

Dr. Allan Berman has worn many hats over the past few years, serving as my committee member, field supervisor, teacher, major professor, colleague, and friend. His support and calm reassurances were of incalculable importance at many points of frustration and discouragement. The help and expertise of Dr. Janet Kulberg through course work, research, comprehensive exams, and dissertation was invaluable. Her contributions in the areas of methodology and research are reflected throughout this work. 
I would also like to offer my sincere thanks to:

Dr. William Vosburgh for the encouragement and leadership he provided as Director of the School Psychology program; Dr. Peter Merenda and Dr. Wayne Velicer, each of whom made unique and essential contributions to this work in the areas of research design and statistics; Dr. Dominic Valentino, a truly dedicated and gifted teacher, for his willingness to venture outside of his area of expertise and for his encouragement to turn the idea for this research into a reality; and Dr. Stewart Cohen for his research expertise, support, and friendship.

I am indebted to Mrs. Catherine Valentino, then Curriculum Coordinator for the North Kingstown School Department, for her receptivity, support, and hard work in implementing this project in the schools; and, to the principals, teachers, and students of the North Kingstown elementary schools for their cooperation and willingness to open their classrooms to this project.

Thanks also to Craig Dickstein and the staff of the U.R.I. Computer Center, and to Joe Rossi and Peter Pothoff, for acting as interpreters between the computer and me. Special thanks and my sincere gratitude to Barbara Van West for sharing her knowledge and skills and for the many hours she spent designing and preparing materials for this project.

I am extremely grateful to my colleagues at Delta Consultants-Al, Tom, Donna, Ann, and Jaffa--for their understanding and support through many periods of depression, high anxiety, and frazzled nerves. And, special thanks to Pat and Judy for their contributions to this work. 
I cannot find words to adequately express the love and respect I have for a group of extraordinary people who have been essential to my growth, both personally and professionally. Thank you Barbara, Jim, Muriel, Stewart, Tom, Alice, and Pamela; and to their children, who helped me keep my priorities in proper perspective.

I am ever-thankful to my parents, Dorothy and Martin Moss, for their support and encouragement to set my goals high and reach for them. I am especially grateful to my mother for the model she provided--for her sensitivity, intelligence, competence, and strength. And, a special gold star to Bob Raphael, my husband, friend, and colleague, who was there at every turning point to share my disappointments and my victories. His loving energy, support, and gift of laughter were available to me throughout it all. It is to him that this work is dedicated. 


\section{TABLE OF CONTENTS}

Page

ABSTRACT ........................... $i$...

ACKNOWLEDGEMENTS ....................... iv

LIST OF TABLES ................................ vii

LIST OF APPENDIXES .................... . $\mathrm{iX}$

Chapter

I. INTRODUCTION ..................... 1

Impulsivity: Symptom or Central Deficit......... 2

Impulsivity and Learning Disability . . . . . . . . . . 5

Modifying Impulsive Behavior .............. 6

Use of Drugs . . . . . . . . . . . . . . . 6

Use of Models ................. . . 7

Training in Inhibition and Scanning Strategies ..... . 9

Behavorial Methods .............. 12

Cognitive Behavioral Strategies . . . . . . . . . 13

The Present Study . . . . . . . . . . . . 16

II. METHOD .............................. 19

Subjects ................. . . 19

Instruments .................. . . 21

Procedure . . . . . . . . . . . . . . 24

III. RESULTS . . . . . . . . . . . . . . . 30

MFFT Latency . . . . . . . . . . . . . 34

MFFT Error . . . . . . . . . . . . . . . . 34

The Pupil Rating Scale ... . . . . . . . . . 37

Achievement Test ............. 37

IV. DISCUSSION .................... 40

Implications for Future Research ........... . 44

Defining Cognitive Tempo ............ . 45

Sample Selection ............... . . 47

Practical Implications .............. . . 4 47

Epilogue ................... 50

APPENDIXES ............................. 51

REFERENCES ................ 60 


\section{LIST OF TABLES}

Table

Page

1 Means ( $X$ ) and Standard Deviations ( $\mathrm{s}$ ) for Dependent Variables . . . . . . . .

2 Product-Moment Correlation Matrix for Pretest Scores..............

3 Summary Table for Analys is of Variance of Transformed MFFT Latency Scores. . . . . . . .

4 Summary Table for Analys is of Variance of MFFT Error Scores........... 36

5 Summary Table for Analys is of Variance of The Pupil Rating Scale Scores ........ 38

6 Summary Table for Analys is of Variance of Achievement Test Scores........... 39

$7 \quad$ Pre- and Posttest Scores for Individual Subjects . 58 


\section{LIST OF APPENDIXES}

Appendix

A "Stop, Listen, Look and Think" Card........

B Instructions for VSI Training . . . . . . .

C Table 7. Pre- and Posttest Scores for Individual Subjects.............
Page

52

54

57 
CHAPTER I

INTRODUCTION

In recent years there has been a marked increase in research focused on the "learning disabled" child. Estimates of the prevalence of this disorder range from one to 30 percent of the school population (Lerner, 1971). Psychologists, educators, and individuals from various other disciplines concerned with the development and education of children have attempted to understand this disorder, develop diagnostic techniques for identifying these children, and devise effective methods of remediation. With few exceptions, these efforts have failed to yield desired results.

A major factor impeding research efforts in this area is the problem of definition. The definition offered by Ross (1976) is fairly typical:

A learning disability is present when a child does not manifest general mental subnormality, does not show an impairment of visual or auditory functions, is not prevented from pursuing educational tasks by unrelated psychological disorders, and is provided with adequate cultural and educational advantages but nonetheless manifests an impairment in academic achievement ... (p. 11)

As the author points out, this type of "definition by exclusion" is circular: "Stripped of those clauses which specify what a learning disability is not, . . . it states, in essence, that a learning disability is an inability to learn" (p. 11). 
Complicating the picture further, is the fact that children who fit this definition have been variously diagnosed as: minimal brain damage (MBD), minimal cerebral dysfunction, hyperactive, hyperkinetic syndrome, and learning disability/dsyfunction, to name a few. These children frequently exhibit a variety of symptoms that are believed to constitute a syndrome. An extensive review of the literature by Clements (1969) revealed 99 symptoms associated with the MBD syndrome. The 10 most frequently cited were:

1. hyperactivity

2. perceptual-motor impairments

3. emotional lability

4. general coordination deficits

5. disorders of attention (short attention span, distractibility, perseveration)

6. impulsivity

7. disorders of memory and thinking

8. specific learning disabilities (reading, writing, arithmetic, spelling)

9. disorders of speech and hearing

10. equivocal neurological signs and electroencephalograph irregularities

A study by Routh and Roberts (1972) designed to test the assumption that children placed in the MBD category exhibit many of these symptoms, revealed that the only significant relationships between symptoms are between fine motor deficits and impulsivity, and between disorders of attention and memory deficits.

Failing to find convincing evidence for the existence of a syndrome, other writers have asked whether there is a more basic cognitive deficit common to learning disabled children that can account for this wide range of behavioral symptoms.

\section{Impulsivity: Symptom or Central Deficit?}

Several investigators have concluded that the critical symptom of the learning disability syndrome is the attention deficit (Douglas, 
1972, 1974; Dykman, Ackerman, Clements \& Peters, 1971; Ross, 1976;

Tarver \& Hallahan, 1974). Learning disabled children tend to be distractible, have short attention spans, have difficulty concentrating-in other words, they have difficulty sustaining selective attention. They are impulsive, and fail to stop and consider alternatives before responding.

Keogh and Margolis (1976) proposed three major aspects of attention that need to be addressed by remedial programs: coming to attention, decision making, and maintaining attention. Impulsivity refers to a deficit in the decision-making function.

Douglas (1974) sees the inability of learning disabled children for "focus, sustain and organize attention and to inhibit impulsive responding" (p. 3) as the fundamental source of their difficulties. She refers to this as the inability to "stop, look, and listen":

These youngsters are apparentiy unable to keep their impulses under control in order to cope with situations in which care, concentrated attention, or organized planning are required. They tend to react with the first idea that occurs to them or to those aspects of a situation which are most compelling. This appears to be the case whether the task requires that they work with visual or auditory stimuli and it also seems to be true in the visual-motor and kinaesthetic [sic] spheres. (Douglas, 1972, p. 275)

Working in the area of cognitive styles, Kagan and his associates

(1964) found that children have different "cognitive" or "conceptual

tempos." He defined cognitive tempo as a psychological disposition that refers to the amount of time a child takes before responding. According to Kagan (1965a):

A child who is prone to respond imoulsively in difficult problem situations (i.e., to initiate a reasoning sequence suggested by the first hypothesis that occurs to him and/or report an answer without sufficient reflection on its validity) is more likely to produce an incorrect response than 
the child whose natural inclinations prompt him to reflect over the differential adequacy of several solution hypothesis and to consider the quality of an "about to be reported answer." (p. 134)

An impulsive approach to problem situations results in a maladaptive cycle in which the child selects a response, experiences failure, becomes anxious about his/her performance, and impulsively selects a second response, which again results in failure. After a period of time, "apathy and hostility may become characteristic reactions toward intellectual situations" (Kagan, 1966a, p. 521).

In order to measure this disposition, Kagan and his associates (1964) devised the Matching Familiar Figures Test (MFFT). In this task the child is shown, for each item, a picture of a familiar object (the standard) and six pictures which are very similar (the variants). The child is asked to find the one picture that is identical to the standard. Number of errors and initial response time are the measured variables. An impulsive child is defined as one who responds very quickly and makes a large number of errors, while a reflective child is one who has relatively long response latencies and makes few errors.

Research with this instrument has shown that the disposition toward fast or slow decision times is moderately stable over time and is generalizable to other tasks with high "response uncertainty"--that is, tasks in which several response alternatives are available simultaneously (Kagan, Rosman, Day, Albert \& Phillips, 1964). Such tasks require decision-making, one of the aspects of attention proposed by Keogh and Margolis (1976).

MFFT performance has also been shown to relate to a variety of cognitive and motor processes, including motor inhibition, analytic- 
relational conceptual style, and field dependence-independence (Messer, 1976). Numerous studies have compared the performance of reflective and impulsive children on school-1ike tasks and have found the latter group to be inferior to their reflective peers on word recognition, inductive reasoning, arithmetic, and short-term memory tasks (Cathcart \& Liedke, 1969; Kagan, 1965b, 1966b; Kagan, Pearson, \& Welch, 1966a; Siege1, Kirasic \& Kilburg, 1973). Taken together, these studies indicate that impulsive children are less efficient processors of information than their reflective peers, performing more like younger children (Epstein, Hallahan, \& Kauffman, 1975; Messer, 1976).

\section{Impulsivity and Learning Disability}

Kagan's MFFT provides an operational definition of a behavior that is believed to be characteristic of learning disabled children. If the construct has validity, children who are described as impulsive in clinical settings should demonstrate an impulsive tempo on the MFFT. Several studies have demonstrated a relationship between cognitive tempo, learning disability, and other behavioral symptoms of the learning disability syndrome.

Keogh and Donion (1972) found that boys with severe learning disabilities had significantly faster reaction times and made more errors on the MFFT than a comparison group of boys who were achieving at grade level. An impulsive cognitive tempo has also been shown to be related to difficulty in sustaining selective attention, hyperactivity, and distractibility (Campbell, Douglas, \& Morgenstern, 1971; Hallahan, Kauffman, \& Bal1, 1973; Kagan, et al., 1964). Keogh (1971) suggests that the tendency of hyperactive children to make decisions too quickly 
may be responsible for learning difficulties they experience. These studies support the notion that impulsivity is a central problem for learning disabled children.

\section{Modifying Impulsive Behavior}

Despite the reported stability of cognitive tempo over time and tasks, numerous researchers have suggested that this tendency might be modifiable. Various means and programs for altering this behavior have been explored.

\section{Use of Drugs}

Drugs, such as methyiphenidate, have been used to alter children's behavior. These drugs, which have a stimulating effect on adults, have a quieting effect on some hyperactive children. Sprague, Barnes and Werry (1970) reported more accurate performance on a recognition task, decreased reaction time, less motor activity, and increases in attention and cooperative behavior when hyperactive and emotionally disturbed children were given methylphenidate. Douglas (1972) and her colleagues demonstrated significant increases in IQ, improved performance on tests requiring sustained attention and motor control, and reductions in impulsivity as a result of drug treatment.

Wender's (1971) review of published studies in this area since 1950 revealed improvement rates varying from 44 to 70 percent. According to Wender, the drug "often decreases impulsivity, excitability, and tantrums, increases planfulness and stick-to-itiveness, and turns a butterfly into a bul1dog" (p. 91). Increased responsiveness to reward and punishment (social controls) and greater inner control were also reported by Wender. 
Grinspoon and Singer (1973) estimated that each day in the United States 200,000 school children receive some form of medication for treatment of hyperactivity. The long-term effects of such treatment are not known. Weiss, Kruger, Danielson, and Elman (1975) looked at measures of emotional adjustment, delinquency, IQ, and academic performance and concluded that methylphenidate was "helpful in making hyperactive children more manageable at home and at school, but did not significantiy effect their outcome after five years of treatment"(p. 159). Keogh and Margolis (1976) attribute the improved academic performance of children to the effects that the drug has on attention.

Ross (1976) strongly urges behavioral approaches to this problem. Even when medication is prescribed, a combination of drug treatment with a behavioral program may increase the likelihood that the resulting behavior change will be attributed to the activity and to personal effort, rather than to the drug.

The use of drugs in the treatment of children's behavior problems is a highly complex and controversial issue. A comprehensive discussion of the matter is beyond the scope of this paper. It is apparent, however, that effective behavioral programs would be the treatment of choice of most physicians and educators. Few would argue with Ross' recommendation that "drug-free alternative interventions for hyperactivity and learning problems . . be given priority" (p. 106).

\section{Use of Models}

One such alternative intervention derives from social learning theory. According to this theory, children acquire many new behaviors by observing others perform those behaviors. The effectiveness of 
observational learning or modeling as a means of acquiring new behaviors has been well documented (e.g. Bandura \& Walters, 1963).

Kagan, Pearson, and Welch (1966a) reasoned that a child's desire to maximize similarity to a desirable adult is an important motive mediating behavior change. They trained impulsive children under two conditions: in the perceived similarity condition, the child was led to believe that he/she and the trainer shared a number of interests and characteristics, while in the low perceived similarity condition the trainer never indicated that he and the child were similar. It was hypothesized that perceived similarity would serve as an incentive for the child to become even more like the model. Since the model valued reflection, it was expected that the child in the perceived similarity condition would become more reflective than his/her peer in the low perceived similarity condition. The hypothesis was not supported.

Yando and Kagan (1968) questioned whether a child's conceptual tempo would be changed as a result of modeling within an ecologicallynatural situation. They investigated the influence of teachers on children's impulsivity during their first year in school. Their results indicated that children taught by experienced reflective teachers became more reflective (i.e. had longer response latencies) than children placed with impulsive teachers. The authors attributed the change to both modeling effects and to direct reinforcement of reflective behavior.

In a study by Meichenbaum and Goodman (1971), the experimenter demonstrated the desired behavior and then encouraged the subject to perform similarly. They found that training was most effective when the subject was explicitily trained to imitate techniques modeled by the trainer. Denney (1972) used a videotaped sequence of an adult 
female modeling reflective behavior, while Ridberg, Parke, and Hetherington (1971) used a series of films with a model of the same age and sex as the subjects. Several studies have used live children as models: Debus (1970) used sixth graders of the same sex as third grade subjects, and Cohen and Przybycien (1974) used sociometrically-selected peer models.

In each of these studies significant results were obtained, indicating that the use of models, whether child or adult, live or filmed, is an effective means of modifying the impulsive behavior of children.

\section{Training in Inhibition and Scanning Strategies}

Some researchers have attempted to modify impulsive behavior by training children to inhibit their impulsive responses. Training procedures which encourage subjects to work slowly and carefully consider response alternatives have generally succeeded in producing longer response latencies (Briggs \& Weinberg, 1973; Debus, 1970; Denney, 1972; Kagan, et al., 1964; Kagan, et al., 1966b). The primary goal of these studies was to effect changes in response latency with the expectation that increases in latency would be accompanied by decreases in error rate. With one exception (Kagan, et al., 1964), no change in error score was found.

Drake (1970) addressed herself to the question of whether different response latencies of impulsive and reflective individuals reflect differences in cognitive approach. Using an eye-marker camera to record eye fixations of subjects while doing the MFFT and a related task, she found that reflective children and adults looked at a greater number of stimulus figures and did so in more detail than impulsive subjects. 
Zelniker, Jeffrey, Ault, and Parsons (1972) found comparable results with the MFFT. However, for an alternate task for which subjects were required to find the one variant that is different from the standard, rather than the one that is identical, different search startegies were observed. With this task, both reflectives and impulsives made more systematic comparisons of the variants. For impulsives this modified strategy transferred to a subsequent administration of the MFFT resulting in significantly fewer errors, although response latencies returned to the initial level.

The authors concluded that superficial scanning of a variant on the MFFT can lead the subject, upon finding no difference, to conclude that it is identical to the standard. However, such behavior on the alternate task, for which a difference must be found, leaves the subject without an appropriate response, and he/she is forced to utilize a more systematic and efficient strategy. It seems likely that the higher level of success experienced by the impulsive subjects in this study increased their motivation and the new search behavior was therefore retained. It is important to note that the improved performance of the impulsives was not accompanied by an increase in response latency, but rather, was due to a change in strategy. Subsequent research (Zelniker \& Opperheimer, 1973) showed that training with this type of task altered the subject's perceptual learning process such that they could effectively discriminate distinctive features of visual stimuli subsequent to training. Subjects who received training on the matching task showed no preference for a particular mode of perceptual learning.

In an attempt to compare the effects of training impulsive children to delay their responses with the effects of training designed to 
improve search strategies, Egeland (1974) found that both techniques resulted in large increases in response time and decreases in errors on the MFFT administered immediately after training. While effects were maintained for the group trained in search strategies, the group trained to delay their responses showed a significant increase in errors on a posttest administered two months after training. The author suggested that while the group trained only to delay was not specifically trained in search strategies, the nature of the tasks used during training may have forced these children to make detailed analyses of visual stimuli, thereby facilitating the use of more efficient problem-solving skills immediately after training.

Ridberg, Parke, and Hetherington (1971) compared effects of a model demonstrating an appropriate scanning strategy with effects of having the model verbalize his strategy. The effectiveness of experimental conditions varied with the level of intelligence of the impulsive subjects: scanning or verbal cues alone were most effective for high IQ subjects (between the group mean of 115 and the cut-off score of 140), while a combination of cues was most effective for low IQ subjects (between 90 and 115).

These findings suggest that while inhibition training is an effective means of getting impulsive children to increase their response latencies, it does not facilitate improvement in the quality of performance. It appears that it is not sufficient to merely teach an impulsive child to delay his/her response; rather, it is also necessary to provide that child with an effective strategy to use while waiting. 
Behavioral Methods

Behavioral methods, which are based upon principles of conditioning, operant procedures, and other behavior modification techniques, have also been used to modify impulsive behavior. This approach emphasizes environmental consequences, with little attention paid to what is going on inside the child. Most studies of the efficacy of these techniques have focused upon a broad category of behavior such as attending or disruptive behavior. Ross (1976) presented an overview of such studies.

O'Leary and his colleagues have done extensive work in this area (Drabman, Spitalnik, \& O'Leary, 1973; O'Leary, Becker, Evans \& Saudargas, 1969; O'Leary \& Drabman, 1971; O'Leary, Drabman, \& Kass, 1973). Exploring the use of token reinforcement programs in the classroom, they have found them to be effective means of modifying disruptive and nonattending behaviors of hyperactive youngsters (O'Leary \& Drabman, 1971).

Briggs (1968) utilized operant behaviors to modify impulsivity and found improvements in both MFFT latency and error scores. Finney (1970) demonstrated an increase in response time without a decrease in error rate. Heider (1971) used attractive toys as reinforcers for good performance and found no significant changes for latency or error scores.

Nelson, Finch, and Hooke (1975) compared the effectiveness of a response-cost procedure with a reinforcement program in order to test the hypothesis that impulsive children have the capacity to respond reflectively, but lack the motivation to do so. Fear of failure and success-seeking are two possible motives for reflective behavior. The response-cost procedure was expected to maximize fear of failure since errors result in a loss of reinforcers, while the reinforcement 
procedure should maximize success-seeking behavior since the child must respond correctly in order to receive the reinforcer. Using emotionally disturbed boys as subjects, they found that both procedures resulted in increases in MFFT latency and decreases in MFFT error scores, although the boys remained more impulsive than their reflective peers. They concluded that, in addition to motivational factors, other important variables must be operating. They suggested a combination of techniques which address the motivational component with those which emphasize cognitive factors.

\section{Cognitive-Behavioral Strategies}

Observations that children often talk to themselves and that these verbalizations appear to serve a self-directing function, led Vygotsky (1962) to propose that the internalization of verbal commands is crucial in the development of voluntary control of behavior. Luria (1961) proposed a developmental sequence in which there is a progression from external to internal control. Prior to two years of age, the child is unable to use speech to direct his/her own behavior. The speech of others can initiate, direct and control the child's behavior, but will not serve to inhibit an action that has already been initiated. During the second stage, the child's own speech controls his/her behavior to some extent. Speech has, according to Luria, a motor component which helps initiate motor behavior but will not inhibit it. For example, if the child tells him/herself "don't push," he/she will push, despite the countermanding self-verbalization. Thus, speech has an "impulsive function" (Meichenbaum and Goodman, 1969). It is only in the third stage, which the child reaches at around age four or five, that "speechfor-self" becomes internalized and assumes a regulatory function. 
Hypothesizing that impulsive children have failed to develop this covert means of self-control, Meichenbaum and Goodman (1969) explored the nature of the relationship between reflectivity-impulsivity and the ability to control motor behavior verbally. They found that selfverbalizations of impulsive children are less effective in controlling their motor behavior than those of reflective children.

Luria (1961) has suggested that hyperactive children can be helped to perform better by training in the internalization of verbal commands. Palkes, Stewart, and Kahana (1968) attempted to test this hypothesis. Using hyperactive boys as subjects and the Porteus Maze Test as the measure of impulsivity, the authors exposed each subject to two thirtyminute training'sessions. Experimental subjects were instructed to "stop, listen, look and think" before performing each training task and to verbalize these directions aloud as they worked. This method of training addressed both the impulsivity and the attention deficit:

"Stop" is the injuction addressed at impulsivity; it could be worded as "Don't be impulsive." "Look and listen" instruct the child to attend to the relevant stimulus dimensions; they might be phrased as "Attend selectively." (Ross, 1976, p. 109)

Control subjects performed the same tasks, but received no verbal training. The posttraining performance of the verbal training group was significantly better than their pretraining performance. The results were interpreted as lending support to Luria's theoretical position, and as suggesting that this type of training can help hyperactive children learn how to control their behavior.

Meichenbaum and Goodman (1971) found that a "cognitive selfguidance" program, in which impulsive children were trained to verbalize directions to themselves as they worked, was effective in improving their 
performance on tasks measuring impulsivity, Performance IQ, and motor ability. While observations of an adult modeling this behavior were effective in increasing latency, the addition of explicit self-instructional training had a dramatic effect on impulsive behavior, bòth in terms of response latency and errors. Finch, Wilkinson, Nelson, and Montgomery (1975) reported similar results with emotionaliy-disturbed impuls ive children.

Bender (1976) compared the effects of verbal self-instruction training with strategy training and a combination of the two approaches, and found that stragegy training was effective in increasing latency, while self-verbalization resulted in both increased latency and reduction of errors. Kendall and Finch (1976) used a combination of cognitivebehavioral (verbal self-instruction) and behavior modification (response cost) techniques to modify the impulsive behavior of a nine year old boy. Improvement in MFFT performance and positive changes in ail target behaviors were evident at the posttreatment evaluation and at a sixmonth follow-up.

Barabash (1977) compared the effectiveness of self-instruction, behavior modification (token fading) techniques, and a combined approach in the modification of cognitive and behavioral impulsivity. Selfinstruction, with its emphasis on internal mediators of behavior, was expected to have the greatest effect on cognitive impuisivity (as measured by MFFT performance), while token fading, which stresses the importance of environmental consequences, was expected to have a greater effect on behavioral impulsivity (as measured by a behavior rating scale). The most effective program for both aspects of impulsivity was a combined treatment package. The group which received self-instruction 
training alone also showed improvement in behavioral impulsivity. Token fading techniques were only slightly more effective than no treatment in the modification of behavioral impulsivity. The results were interpreted as supporting a cognitively-mediated theory.

\section{The Present Study}

The present study was designed to modify the impulsive behavior of learning disabled boys. The training procedure used represents a combination of several of the approaches discussed earlier.

The verbal self-instructional method (Meichenbaum, 1977) provided the basis for the training procedure. This approach addresses both the child's cognitions and his behavior. The "stop, listen, look and think" principles (Palkes, Stewart, \& Kahana, 1968) were incorporated into the training procedure in order to encourage the children to inhibit their impulsive tendencies and attend to the task at hand. The desired behaviors were modeled by the tutors, and the children were required to practice the new strategies in the presence of the tutors. The children were also encouraged to employ the new strategies in the classroom, and were given "cue cards" to facilitate generalization.

Most of the studies reviewed earlier trained children with the MFFT or other picture-matching and visual-perceptual tasks in the hope that the new behaviors would generalize to classroom activities. However, behavior theory tells us that generalization of a behavior is most likely to occur when the situation in which the learning takes place most closely resembles the naturalistic setting: 
Behavior therapists have come to recognize that treatment is most effective when its focus is on the target of intervention and takes place in the setting where the troublesome behavior is found. Thus, where children are in trouble because they fail to sit still and attend to their tasks in the classroom, treatment had best take place in the classroom and not in the therapist's consulting room. If, for practical reasons, treatment cannot take place in the class, the focus of treatment should be as similar as possible to the classroom situation. . (Ross, 1976, p. 116)

With this principle in mind, the intervention used in the present study was conducted in the child's school, and utilized academic tasks, similar in nature to those that the child encounters in the classroom. Another group was trained in a similar manner, using non-academic tasks in order to assess the relative effectiveness of using school-like tasks in training. Two traditional tutoring groups--one trained with academic, the other with non-academic tasks--were included as control groups.

The hypothesis of the study was that the verbal self-instructional program, utilizing the "stop, listen, look and think" principles, would produce more reflective behavior in impulsive learning disabled boys than the more traditional approach.

The following predictions were made:

Prediction 1: The verbal self-instructional program, applied to academic tasks, will produce significant improvement in MFFT latency and error scores, achievement test scores, and behavior ratings made by teachers.

Prediction 2: The verbal self-instructional program, applied to non-academic tasks, will produce significant improvement in MFFT latency and error scores, and will have little or no effect on achievement test scores and behavior ratings made by teachers. 
Prediction 3: Traditional tutoring, using academic tasks will have no significant effect on any of the dependent measures.

Prediction 4: Traditional tutoring, using non-academic tasks, wi11 have no significant effect on any of the dependent measures. 


\section{CHAPTER II}

\section{METHOD}

\section{Subjects}

Subjects for the study were 76 children from 30 classrooms in five elementary schools in a middle-class, suburban community in Rhode Island. All subjects had the following characteristics:

1. Sex: Since four to 10 times as many boys as girls are diagnosed as learning disabled (Spears \& Weber, 1974), only males were used as subjects.

2. Age and grade: A11 subjects were seven to 11 years of age, in the second, third or fourth grade in school.

3. Intelligence level: Since all definitions of learning disability include the requirement that the child have at least average intellectual ability, all subjects were required to attain a scaled score of eight or higher on the Vocabulary subtest of the Wechsler Intelligence Scale for Children-Revised (WISC-R). This score corresponds to an IQ score of 90 (Wechsler, 1974).

4. Medical history: No child had a medical and/or psychological diagnosis indicating structural brain damage or emotional disturbance.

5. Medication: No subject was, according to school report, taking medication prescribed to alter behavioral symptoms related to his learning difficulties. 
6. Learning disability: A child was considered to be learning disabled if he received a total score of 72 or less on The Pupil Rating Scale completed by his teacher. This score represents the mean for learning disabled children (60.82) plus one standard deviation (11.63) as reported by Myklebust (1971). The pretraining mean score for the present sample was 56.50 with a standard deviation of 7.12 , indicating that the group was well within the range established for learning disability.

7. Impulsivity: A child was considered to be impulsive if he had a mean latency score of less than 17 seconds on the MFFT; error scores were not used as a criterion for inclusion in the study: Denney (1973) found that he was able to correctly classify 63 percent of his subjects on the basis of latency score alone. Similar findings have been reported by Kagan (Kagan, 1966a; Kagan et al., 1964).

In the various studies cited by Messer (1976), the mean latency scores for samples of first and second graders considered to be impulsive ranged from 6.7 to 11.6 seconds, with a mean of means of 9.9 seconds. Sample means for third to fifth graders ranged from 8.1 to 17.0 seconds, with a mean of means of 9.9 seconds. The pretraining mean latency score for the present sample was 9.4 with a standard deviation of 3.5 , suggesting that this group was comparable to those defined as impulsive by previous researchers.

Error scores are variable and lack adequate reliability (Messer, 1976). However, they are important in differentiating the impulsive child whose rapid tempo causes him to do poorly from the fast-accurate child who is able to respond quickly and still do well. In light of the requirement that the children be learning disabled in order to 
participate in the present study, it seemed unlikely that any fastaccurate children would be identified.

Mean error scores for the impulsive samples cited by Messer ranged from 21.0 to 25.8 with a mean of means of 24.1 for first and second graders, and from 8.4 to 18.0 with a mean of means of 11.4 for third to fifth graders. The mean error score for the present sample was 12.4, with a standard deviation of 4.7 .

\section{Instruments and Materials}

Vocabulary Subtest of the WISC-R

This test was used as a screening measure to insure that all subjects were of at least average intelligence. A verbal measure of IQ was used since MFFT performance correlates with measures of performance IQ (Messer, 1976). Split-half reliability coefficients for WISC-R Vocabulary scores range from .70 to .86 for children in the seven to 11 age range; correlations with Verbal IQ range from .71 to .84 (Wechsler, 1974).

\section{Matching Familiar Figures Test}

The MFFT has been used by Kagan and subsequent researchers in the area of cognitive tempo to classify a total population. Using a median-split procedure, children who are above the group median for response time and below the median error score are considered to be reflective, while those who are below the median response time and above the median error score are categorized as impulsive. Two-thirds of most samples fall into one of these two categories (Messer, 1976). The remaining third--those who are fast and accurate or slow and inaccurate--have been largely ignored in research studies. 
Since only impulsive children were to be subjects of the present research, the operational definition of impulsivity was, as described earlier, based upon earlier studies which utilized the median-split procedure.

The same form of the MFFT was used for pre-and posttesting. Test-retest reliabilities range from .58 to .96 for response latency and from .39 to .80 for error scores over periods from one to eight weeks, for children six to 10 years of age (ilesser, 1976).

Mean latency scores were used as one of the criterion measures for inclusion in the study; both latency and error scores were used for pre- and posttesting.

Stanford Achievement Test (SAT)

Selected subtests from the SAT Primary II Battery, including Word Meaning, Paragraph Meaning, Spelling, Arithmetic Computation, and Arithmetic Concepts, were used as the measure of achievement. This test is designed for children in grades 2.5 to 3.9 ; thus, it was considered to be appropriate for second to fourth graders experiencing learning difficulties. Split-half reliability coefficients for the SAT range from .85 to .94 (Kelley, Madden, Gardner, \& Rudman, 1964).

\section{The Pupil Rating Scale}

The Pupil Rating Scale is a behavior rating scale designed for use by classroom teachers to identify and classify children with learning disabilities. The total score was used as a criterion measure for inclusion in the study, and as a posttest measure of behavioral changes resulting from the training programs. Correlations above. 90 are reported between total score and all subscores, 
with the exception of Motor Coordination for which the correlation is .64 .

The Pupil Rating Scale has been shown to successfully discriminate between learning disabled children and a normal control group who differed significantly on 47 out of 50 psychoeducational variables, including a variety of cognitive, academic, and perceptual tasks (Myklebust, 1971). Teacher ratings are good predictors of learning difficulties, frequently surpassing formal test procedures (Haring \& Ridgway, 1967). Instructions to the teacher were altered so that the emotionally-loaded term "learning disability" did not appear.

Stop, Listen, Look and Think Card

A cue card, measuring $5-1 / 2$ by $8-1 / 2$ inches, was designed to illustrate the "stop, listen, look and think before responding" rules. The card was adapted from those used by Palkes, Stewart and Kahana (1968). A copy of the card may be found in Appendix A.

\section{Training Tasks}

Assignments from the following five academic subject areas were used for Academic training: word study skills (auditory discrimination), reading (word meaning), reading comprehension, arithmetic computation, and spelling. The spelling words were taken from the Wide Range Achievement Test, Spelling subtest (Jastak \& Jastak, 1965); the other tasks were adapted from the 1973 revision of the SAT (Madden, et al., 1973). The revised test is completely different from the 1964 edition which was used for pre- and posttesting. Tasks were selected from achievement tests in order to provide a sufficiently wide range of difficulty level to meet the 
needs of all of the subjects. The tasks taken from the SAT were all in multiple choice format which provided "response uncertainty"--a condition that exacerbates impulsive tendencies.

Non-academic tasks consisted of the Children's Embedded Figures Test (Goodenough \& Eagle, 1963), Raven's Coloured Progressive Matrices (Raven, 1965), an adaptation of the T.V. game show "Concentration" using twelve pairs of playing cards, the Developmental Test of VisualMotor Integration (Beery \& Buktenica, 1967), and WISC-R Mazes (Wechsler, 1974).

\section{Procedure}

Screening and Pretesting

Teachers of grades two through four were asked to complete the Pupil Rating Scale for all boys in their classes whom they believed to be having learning problems. Parental permission to participate in the study was obtained for all children who received a total score of 72 or lower. These potential subjects were then given the Vocabulary subtest of the WISC-R and the MFFT. Those who met the criteria established for these measures, as well as the other subject criteria outlined above, were selected as subjects.

Alternate items from each of the SAT subtests were used for preand posttesting. Approximately half the subjects were pretested with each form, and the alternate form was then used for posttesting. Testing was conducted in small groups, in two half-hour sessions. All testing was conducted by the tutors. 


\section{Tutors}

The tutors were 15 undergraduate women students enrolled at the University of Rhode Island. Most were juniors and seniors, majoring in Psychology, Education, Child Development, or Speech. They received three elective credits for participating in the project by registering for Psychology 489: "Special Projects in Psychology." The course was run by the present author and supervised by a Psychology Department facul ty member.

The tutors met weekly with the instructor. During the initial weeks of the semester they read assigned materials on learning disabilities and impulsivity. They were given an overview of the project and were trained in the administration of the various test instruments. Based upon their schedules, transportation, and other practical considerations, they were assigned to a school, to four or five subjects, and to either the Traditional Tutoring $(T T)$ or Verbal Self-Instructional (VSI) method; assignments were random wherever possible. Children were assigned to either the Academic (A) or Non-Academic (NA) condition such that approximately half of each tutor's "caseload" and half of the children in each school were in each of the two conditions.

VSI tutors were assigned additional readings which explained the training method that they would be using; TT tutors did not read these materials until the study was completed. Each week VSI tutors met with the instructor to discuss the VSI method and its application to that week's tasks, and to practice their roles using each other as subjects. TT tutors met each week to discuss their experiences and the ways in 
which they were working with the youngsters. As a requirement for the course, all tutors were asked to maintain logs of their sessions, including subjective descriptions of their experiences.

The Training

Most of the studies reviewed earlier produced positive changes in MFFT performance after one training session. Others trained children in three to eight sessions, individually and in small groups, over oneday to four-week periods of time. Based upon these studies, the number of training sessions for the present study was set at five, one-half hour in length, one session per week. Training was initiated after the pretesting was completed and was conducted over a seven-week period due to student absences and varying university and school department schedules.

Each subject was assigned to one of four conditions:

1. Verbal Self-Instruction/Academic (VSI-A): Children in this condition were instructed in the VSI method and applied the techniques to academic tasks.

2. Verbal Self-Instruction/Non-Academic (VSI-NA): This group learned the VSI method in the context of non-academic tasks.

3. Traditional Tutoring/Academic (TT-A): Children in this condition were given the same academic tasks as the VSI-A group, and were helped by the tutors in any way that they (the tutors) deemed appropriate. The TT tutors were given no information about the VSI method.

4. Fraditional Tutoring/Non-Academic (TT-NA): Children in this condition were given the non-academic tasks and were helped by the tutors. 
Each week the tutor went to the child's classroom at the appointed time and took him to a room or area in the school that was designated for the tutorial session. The tutor presented the task to be worked on that day and helped the child complete it.

The VSI tutors introduced the method in accordance with written directions which may be found in Appendix $B$. The training procedure was adapted from Meichenbaum (1977). An excerpt is presented below:

I want to show you some new ways to work. This new way is called: "Stop, Listen, Look and Think" (show cue card). See, we're going to use this card to help remind you of what you are supposed to do. (Explain card.)

Here's a reading paper. Let's pretend that I'm you and (teacher's name) has just handed this paper out to the class. I'm going to think out loud while I do it to make sure that I don't forget anything. I want you to 7 isten and watch what I do and then I want you to try to do it the same way.

$0 . K$. My teacher has just given me this assignment. What is it that I have to do? First, I will STOP, like it says here (refer to card) and LISTEN carefully to the directions that my teacher is giving. (Pretend to be 1 is tening). Oh, it's a reading paper. (Teacher's name) said to read the sample sentence first and circle the word that belongs in the sentence. Let me LOOK (point to card). Here is the word "sample," so this must be the one. (Read from paper) "We saw a happy boy and a sad girl. The girl was . . crying. . . flying. . . purple. . asleep." Hmmm

. . I'd better check the sentence again. .

The tutor continued in this manner until the child indicated that he was ready to try it himself. He then started from the beginning, with the tutor cueing him to verbalize each step in the procedure. The steps were as follows:

1. The tutor performed the task while instructing herself aloud and verbalizing the "stop, listen, look and think" rules.

2. The child performed the task as the tutor did; the tutor gave him cues as to what to say as he worked. 
3. Gradually, the child was able to perform the task with selfinstructions without too much prompting from the tutor.

4. Once the child mastered this technique, the tutor encouraged him to whisper the instructions to himself. Without diminishing the amount of self-instruction, the volume was decreased. (In the second session the child was encouraged to speak in a low voice. The tutors discussed the reasons for this--e.g. he might disturb others while he works).

5. By the fourth session the child was to be ready to guide his performance with "private speech." (The tutors pointed out to the children the analogy with learning how to read: At first they had to do it out loud, and gradually they learned how to do it without vocalizing).

The children were encouraged to use the VSI method whenever they did any task. Each was given a Stop, Listen, Look and Think cue card to take back to his classroom, and was instructed to bring it with him each week when he met with the tutor.

$T T$ tutors were instructed to help the children complete the assignment in any way they thought was appropriate; no other directions were given.

At the end of the last tutorial session, the tutors readministered the MFFT. Although the posttesting was conducted by the tutor who worked with that child, the tutors had no knowledge of that child's pretest scores. The alternate form of the achievement test was administered the following week(s) in small groups.

The Pupil Rating Scale was distributed to the teachers and they were asked to rate the children again, this time focusing on the child's classroom performance during the last six to eight weeks since 
training began. The teachers were given no specific information about the nature of the tutoring until all data were collected. During a "debriefing" session, several of the teachers reported that they had observed some students whispering directions to themselves and had seen them using the cue cards in the classroom. They concluded that these observations were related to the training sessions, and assumed that all participating students were receiving the same instructions. 


\section{CHAPTER III}

\section{RESULTS}

A $2 \times 2 \times 2$ factorial analysis of variance with repeated measures was conducted for each of the four dependent variables. The three factors were: Training (VSI and TT), Task ( $A$ and NA), and Trials (pre and post). The four dependent variables were: MFFT latency score, MFFT error score, total score for The Pupil Rating Scale, and composite score for the achievement test. The analysis of variance procedure was utilized in order to permit comparisons of the effects of the various treatment conditions. The .05 level of significance was used for these analyses, with the more conservative .01 level used for tests of homogeneity of variance, as suggested by Winer (1962). Table 1 presents the pre- and posttest means and standard deviations for the dependent variables. Product-moment correlations between dependent measures at pretest are reported in Table 2 . Correlations between latency and error scores $(r=-.401)$, error and achievement scores $(r=-.349)$, and Pupil Rating and achievement scores $(r=.544)$ are statistically significant, corresponding to common variance percentages of $16.1,12.2$, and 29.6 , respectively. While the first two account for relatively small portions of shared variance, the last is of sufficient magnitude to suggest practical significance. Hence, The Pupil Rating Scale and the achievement test may be measuring the 
TABLE 1

MEANS $(\bar{X})$ AND STANDARD DEVIATIONS (SD)

FOR DEPENDENT VARIABLES

VSI

TT

A

NA

A

NA

MFFT Latency ${ }^{\mathrm{a}}$

\begin{tabular}{|c|c|c|c|c|}
\hline $\operatorname{Pre} \frac{\bar{x}}{(s d)}$ & $\begin{array}{r}10.13 \\
3.37\end{array}$ & $\begin{array}{l}9.65 \\
3.98\end{array}$ & $\begin{array}{l}8.71 \\
2.23\end{array}$ & $\begin{array}{l}9.01 \\
3.82\end{array}$ \\
\hline $\operatorname{Post} \begin{array}{c}\bar{x} \\
(s d)\end{array}$ & $\begin{array}{r}16.93 \\
8.54\end{array}$ & $\begin{array}{r}14.85 \\
5.77\end{array}$ & $\begin{array}{r}13.51 \\
7.74\end{array}$ & $\begin{array}{r}11.13 \\
4.95\end{array}$ \\
\hline$n$ & 19 & 19 & 19 & 19 \\
\hline
\end{tabular}

MFFT Latency Transformed ${ }^{b}$

\begin{tabular}{crrrr}
\hline $\operatorname{Pre}_{(\mathrm{X}}$ & 11.03 & 12.12 & 12.22 & 13.12 \\
$\operatorname{Post}^{\bar{X}}(\mathrm{sd})$ & 4.01 & 4.74 & 3.15 & 5.36 \\
& 8.00 & 8.05 & 9.90 & 10.98 \\
$\mathrm{n}$ & 5.38 & 3.93 & 5.93 & 5.42 \\
\hline
\end{tabular}

MFFT Error

\begin{tabular}{crrrr}
\hline $\bar{X}$ & 13.05 & 11.68 & 13.11 & 11.84 \\
$\operatorname{Pre}(s d)$ & 5.38 & 5.15 & 4.25 & 4.36 \\
$\operatorname{Post}_{(\mathrm{X}}(\mathrm{sd})$ & 7.58 & 7.47 & 8.79 & 10.26 \\
$\mathrm{n}$ & 4.00 & 4.31 & 2.57 & 5.41 \\
\hline
\end{tabular}


TABLE 1-Continued

\begin{tabular}{|c|c|c|c|c|}
\hline & \multicolumn{2}{|c|}{ VSI } & \multicolumn{2}{|c|}{$T T$} \\
\hline & $A$ & NA & $A$ & NA \\
\hline \multicolumn{5}{|c|}{ The Pupil Rating Scale } \\
\hline $\operatorname{Pre} \begin{array}{c}\bar{x} \\
(s d)\end{array}$ & $\begin{array}{r}56.46 \\
8.88\end{array}$ & $\begin{array}{r}53.93 \\
5.03\end{array}$ & $\begin{array}{r}53.50 \\
8.51\end{array}$ & $\begin{array}{r}57.60 \\
6.15\end{array}$ \\
\hline $\operatorname{Post}\left(\begin{array}{c}\bar{x} \\
(s d)\end{array}\right.$ & $\begin{array}{r}65.31 \\
9.12\end{array}$ & $\begin{array}{r}60.50 \\
6.32\end{array}$ & $\begin{array}{r}60.17 \\
8.38\end{array}$ & $\begin{array}{l}64.80 \\
10.00\end{array}$ \\
\hline$n$ & 13 & 14 & .12 & 15 \\
\hline \multicolumn{5}{|c|}{ Achievement Test } \\
\hline $\operatorname{Pre} \begin{array}{c}\bar{x} \\
(s d)\end{array}$ & $\begin{array}{l}61.79 \\
24.82\end{array}$ & $\begin{array}{l}53.00 \\
20.79\end{array}$ & $\begin{array}{l}54.42 \\
22.89\end{array}$ & $\begin{array}{l}53.95 \\
16.82\end{array}$ \\
\hline $\operatorname{Post} \underset{(s d)}{\bar{X}}$ & $\begin{array}{l}62.32 \\
24.86\end{array}$ & $\begin{array}{l}56.32 \\
17.37\end{array}$ & $\begin{array}{l}61.32 \\
26.17\end{array}$ & $\begin{array}{l}59.00 \\
23.32\end{array}$ \\
\hline$n$ & 19 & 19 & 19 & 19 \\
\hline
\end{tabular}

"Latency Scores are reported in "seconds".

${ }^{b}$ Transformed score $T X=100 / X$. 
TABLE 2

PRODUCT-MOMENT CORRELATION MATRIX FOR PRETEST SCORES $(N=76)$

\begin{tabular}{|c|c|c|c|c|}
\hline & Latency & Error & $\begin{array}{l}\text { Pupil } \\
\text { Rating }\end{array}$ & Achievement \\
\hline Latency & 1.000 & $-0.401 *$ & -0.177 & -0.104 \\
\hline Error & & 1.000 & -0.187 & $-0.349 *$ \\
\hline Pupil Rating & & & 1.000 & $0.544 *$ \\
\hline Achievement & & & & 1.000 \\
\hline
\end{tabular}

${ }^{\star} p<.05$ 
same basic attribute to an appreciable extent, and this was considered in the interpretation of results. Since results for both measures were essentially the same, this presented no major interpretive problems.

\section{MFFT Latency}

The assumption of homogeneity of variance was violated for the latency data $[\underline{F} \max (8,18)=14.67, p<.01]$. To reduce the variability, the data were transformed using the reciprocal of each score and multiplying the 100 (in order to avoid values which approach zero). Thus, the transformation took the form: $T X=100 / X$. With the transformed data the variability was reduced to acceptable limits $[\underline{F} \max (8,18)=$ $2.69, p>.01]$.

Analysis of variances of the transformed data (Table 3) yielded a significant Training main effect $[\underline{F}(1,72)=4.69, p<.05]$ with VSI groups demonstrating longer latencies, overall, than TT groups. A significant Trials main effect was also found $[\underline{F}(7,72)=14.59, p<$ $.001]$, indicating that the total sample improved (had longer latencies) from pre- to posttest. The Task main effect was not significant, and no significant interactions were observed.

\section{MFFT Error}

Error score data meet the assumption of homogeneity of variance $[\underline{\max }(8,18)=1.83, \mathrm{p}>.01]$. Analys is of variance (Table 4) yielded a significant Trials main effect $[\underline{F}(1,72)=40.32, p<.001]$, indicating that the sample as a whole improved (made fewer errors) from pre- to posttest. No other main effect or interaction was significant. 


\section{TABLE 3}

SUMMARY TABLE FOR ANALYSIS OF VARIANCE

OF TRANSFORMED MFFT LATENCY SCORES

\begin{tabular}{lrrrrr}
\hline Source & SS & df & MS & F & $p$ \\
\hline Training (Tr) & 116.434 & 1 & 116.434 & 4.69 & $<.05$ \\
Task (Ta) & 23.031 & 1 & 23.031 & 0.93 & n.s. \\
Tr X Ta & 1.644 & 1 & 1.644 & 0.09 & n.s. \\
Error & 1786.559 & 72 & 24.813 & & \\
& & & & & \\
Triais (Tri) & 316.754 & 1 & 316.754 & 14.59 & $<.001$ \\
Tri X Tr & 16.431 & 1 & 16.431 & 0.76 & n.s. \\
Tri X Ta & 1.768 & 1 & 1.768 & 0.08 & n.s. \\
Tri X Tr X Ta & 3.519 & 1 & 3.519 & 0.16 & n.s. \\
Error & 1562.940 & 72 & 21.708 & & \\
\hline
\end{tabular}


TABLE 4

SUMMARY TABLE FOR ANALYSIS OF VARIANCE

OF MFFT ERROR SCORES

\begin{tabular}{lrrrrr}
\hline \hline Source & \multicolumn{1}{c}{ SS } & df & MS & F & $p$ \\
\hline Training (Tr) & 42.112 & 1 & 42.112 & 1.59 & n.s. \\
Task (Ta) & 3.788 & 1 & 3.788 & 0.14 & n.s. \\
Tr X Ta & 6.736 & 1 & 6.736 & 0.25 & n.s. \\
Error & 1908.250 & 72 & 26.503 & & \\
& & & & & \\
Trials (Tri) & 576.417 & 1 & 576.417 & 40.32 & $<.001$ \\
Tri X Tr & 34.104 & 1 & 34.104 & 2.39 & n.s. \\
Tri X Ta & 37.999 & 1 & 37.999 & 2.66 & n.s. \\
Tri X Tr X Ta & 5.158 & 1 & 5.158 & 0.36 & n.s. \\
Error & 1029.308 & 72 & 14.296 & & \\
\hline
\end{tabular}




\section{The Pupil Rating Scale}

Teachers of 22 subjects did not return the posttraining rating scale. These subjects were eliminated from analyses for this measure, and results are reported for the 54 remaining subjects.

The assumption of homogeneity of variance was met for these data $[\underline{\max }(8,14)=3.96, p>.01]$. Analys is of variance (Table 5) yielded a significant Training $X$ Task interaction $[F(7,50)=4.31, p<.05]$. None of the simple effects tests was significant, suggesting that the interaction was affected by random differences existing between groups at the time of pre-testing.

A significant Trials main effect was also observed $[F(1,50)=$ $55.83, p<.001]$, indicating that the sample as a whole was rated higher by teachers at the time of posttest. No other main effects or interaction was significant.

\section{Achievement Test}

The assumption of homogeneity of variance was met for achievement test data $[F \max (8,18)=2.42, p>.01]$. Analysis of variance (Table 6) yielded a significant Trials main effect $[F(1,72)=6.82$, p <.05], indicating a significant overall improvement in achievement test performance (as measured by the composite score) from pre- to posttest. No other main effect or interaction was significant. 
TABLE 5

SUMMARY TABLE FOR ANALYSIS OF VARIANCE

OF THE PUPIL RATING SCALE SCORES

\begin{tabular}{|c|c|c|c|c|c|}
\hline Source & SS & $d f$ & MS & $F$ & $p$ \\
\hline Training (Tr) & 0.027 & 1 & 0.027 & 0.00 & n.s. \\
\hline Task (Ta) & 3.250 & 1 & 3.250 & 0.03 & n.s. \\
\hline $\operatorname{Tr} \times \operatorname{Ta}$ & 432.992 & 1 & 432.992 & 4.31 & $<.05$ \\
\hline Error & 5019.957 & 50 & 100.992 & & \\
\hline Trials (Tri) & 1437.172 & 1 & 1437.172 & 55.83 & $<.001$ \\
\hline $\operatorname{Tri} \times \operatorname{Tr}$ & 4.031 & 1 & 4.031 & 0.16 & n.s. \\
\hline Tri $\times$ Ta & 5.082 & 1 & 5.082 & 0.20 & n.s. \\
\hline $\operatorname{Tri} \times \operatorname{Tr} \times \operatorname{Ta}$ & 13.214 & $T$ & 13.214 & 0.51 & n.s. \\
\hline Error & 1287.087 & 50 & 25.742 & & \\
\hline
\end{tabular}


TABLE 6

SUMMARY TABLE FOR ANALYSIS OF VARIANCE

OF ACHIEVEMENT TEST SCORES

\begin{tabular}{lrrrrr}
\hline \hline Source & SS & df & MS & $F$ & $p$ \\
\hline Training (Tr) & 53.250 & 1 & 53.250 & 0.06 & n.s. \\
Task (Ta) & 733.813 & 1 & 733.813 & 0.80 & n.s. \\
Tr X Ta & 342.000 & 1 & 342.000 & 0.37 & n.s. \\
Error & 65820.000 & 72 & 914.167 & & \\
& & & & & \\
Trials (Tri) & 592.102 & 1 & 592.102 & 6.82 & $<.05$ \\
Tri X Tr & 156.023 & 1 & 156.023 & 1.80 & n.s. \\
Tri X Ta & 2.129 & 1 & 2.129 & 0.02 & n.s. \\
Tri X Tr X Ta & 50.945 & 1 & 50.945 & 0.59 & n.s. \\
Error & 6248.727 & 72 & 86.783 & & \\
\hline
\end{tabular}


CHAPTER IV

DISCUSSION

It was expected that children trained with the VSI method would demonstrate greater improvement on the dependent measures than groups tutored in a more traditional manner. This prediction received partial support from MFFT latency results, with VSI subjects demonstrating significantly longer latencies than TT subjects. The sample as a whole improved significantly from pre- to posttest on all four dependent measures. Contrary to predictions, none of the Training $X$ Trials or Training $X$ Trials $X$ Task interactions was significant. Thus, both VSI and TT interventions seemed to be effective in modifying impulsive and maladaptive problem-solving and classroom behaviors of children with learning problems.

Previous studies have demonstrated the superiority of the VSI method over various control methods in producing more reflective performance on the MFFT and, in some instances, improved academic performance and classroom behavior as we11. These findings were not replicated in the present study, and it seems likely that methodolgical and subject differences between those studies and the present one have contributed to the discrepancies in findings.

Comparison of subject populations sampled in many of the earlier studies with the population sampled for the present project indicates 
at least two major differences: (a) Subjects for the present study were identified by their teachers as having learning difficulties and their scores on The Pupil Rating Scale met the criteria for learning disability; and (b) Error scores were not used as a criterion for inclusion in this study.

Children with learning problems experience a great deal of failure and frustration in the classroom. Time spent outside the classroom with an extremely supportive, enthusiastic teacher is likely to be a very positive experience for these youngsters. The experience of success in this environment may have helped improve self-confidence and reduce anxiety for some youngsters. The tutors' logs suggest that they often acted as counselors in their attempts to help these youngsters. This was especially true for the TT tutors who had no specific procedure to follow during their sessions. Thus, the therapeutic nature of the tutorial relationship may have been a more powerful treatment for these children than the differential effects of the two training methods.

With regard to error scores, it was anticipated that the learning disability criterion would minimize the possibility that any "fastaccurate" children would be included in the subject sample. Results indicate that the sample as a whole, with a mean error score of 12.4 and a standard deviation of 4.7 , was in fact within the "impulsive" range established by previous research. Nevertheless, there were a few subjects who made relatively few errors and seem to be, therefore, fast-accurate, rather than impulsive. 
Similarly, mean MFFT latency score for the present sample was 9.4 with a standard deviation of 3.5 , which is comparable to means obtained in previous studies. However, some individual subjects had mean latency scores that were considerably higher than the group mean. Is a child who has a mean latency score of 16 seconds impulsive? The more basic question is: Where do we draw the line? In fact, cognitive tempo is a continuous variable. Dichotomization into discrete groups is artificial and raises some serious methodological, conceptual, and statistical problems. In addition, there appears to be considerable overlap among samples defined by different researchers as impulsive and reflective. In other words, one researcher's reflectives may be another's impulsives (Messer, 1976, p. 1028). It seems, then, that a more stringent definition of terms is needed.

The present study was modeled after Meichenbaum and Goodman's (1971) study. They found between-group differences in MFFT latency score and for several other measures that were not included in the present study; they did not include measures of academic achievement. As in the present case, between-group differences in MFFT error scores and measures of classroom behavior were not significant. Thus, for those measures that are comparable, results are essentially the same.

There are some noteworthy differences between the Meichenbaum and Goodman (1971) study and the present one. The former included both an attention control group in which the subjects were exposed to the same materials and were seen for the same number of sessions as the VSI subjects, and a no treatment control group. While the TT groups in 
the present study were designed as attention control groups, they seem not to have functioned as such. TT tutors were given information about impulsivity and learning disabilities and were highly motivated to help these youngsters. Their logs indicate that, like the VSI tutors, they also encouraged the children to work slowly and to think a problem through before responding. And, as described earlier, they often acted as counselors.

Thus, the TT groups do not appear to be comparable to Meichenbaum and Goodman's attention control groups and may not have served as effective control groups. The differences between the two training methods were not, therefore, as great as had been intended, which may account for the lack of significant differences between them.

A no treatment control group was not included in the present study so that some form of one-to-one tutoring would be provided to each child who participated in the study. Without this type of control group it is impossible to assess the effectiveness of these two methods over no treatment at al1. Would similar changes occur without any intervention due to maturation? In light of the degree of change observed and the brief period of time involved, this seems highly unlikely. The Pupil Rating Scale results are most highly suspect since a halo effect could have occurred, with teachers perceiving all participants as having improved or rating them as such in order to "help" the project and its staff. MFFT and achievement tests, however, were administered by tutors who, at posttest, had no knowledge of their students' pretest scores. 
Feedback from both teachers and tutors indicated that they felt that additional sessions, over an extended period of time, were necessary for these children to become proficient with the VSI strategy. Their anecdotal reports indicated that an immediate, dramatic effect was observed for some youngsters in the VSI groups.

The findings and issues discussed above suggest additional strategies for future research.

\section{Implications for Future Research}

Results of the present study did not demonstrate the superiority of VSI techniques over more traditional remedial approaches. However, the findings do indicate that the VSI approach is at least as effective as TT. In light of the dearth of alternative approaches it seems inadvisable and somewhat premature to discontinue research in this area. Findings of previous studies, together with the anecdotal reports from teachers in the present study provide ample justification for further exploration. Moreover, perhaps the most useful aspect of this study has been its indications of the need for researchers to make several modifications in design before further research is undertaken.

One question raised by this study is whether the VSI method might have produced greater gains than TT if more training time had been provided. It is also important to be able, in future studies, to differentiate between gains due to the teaching approach and those resulting from the counseling that may have inadvertently been provided in the tutorial sessions. Effects due to maturation must also be assessed. 
In order to address these questions, it is suggested that future studies include, in addition to VSI and TT groups, a counseling group in which tutors spend the session talking to the children, and a no treatment control group. In order to control for experimenter effects, tutors should be trained to be objective and to avoid the close personal involvement that transpired in the present study. While this will address the methodological issues, it may limit generalizability of findings since the personal relationship between child and teacher is an essential part of any learning. The course of the program should be extended to a semester or full academic year in order to allow time for VSI subjects to become proficient with the strategy.

In addition to studies designed to validate a particular strategy for remediation, research is needed to clarify important methodological and theoretical issues in this area.

\section{Defining Cognitive Tempo}

What is impulsivity and why do we want to modify it? These are basic questions that have not been satisfactorily addressed by researchers in this area. The assumption is made that impulsivity is "bad," while a reflective approach is desirable. The tendency to act quickly without taking sufficient time to assess response alternatives may be maladaptive, and few would contest attempts to modify this response style if it is interfering with the child's ability to experience success. While the double median-split procedure that is generally applied to MFFT results undoubtedly does identify the truly 
impulsive child, it may also place many non-impulsive children in this category as well.

A speedy yet accurate performance is consistently reinforced within the classroom, and in our society in general; thus the fastaccurate child is likely to meet with success in school. Despite this fact, these youngsters, along with those identified as slow-inaccurate, have been virtually ignored in research studies since they do not fit within the bipolar model of cognitive tempo that has been proposed by Kagan. If a child who is impulsive at the outset of a study becomes fast-accurate as a result of training, is this not a desirable outcome? His/her teacher would probably think so, but the researcher would not. It seems, then, that our current theoretical conception of cognitive tempo is not in line with its practical applications.

Using the double median-split procedure, approximately one-third of any given sample will be classified as impulsive, one-third as reflective, with the remaining third falling into the fast-accurate and slow-inaccurate categories (Messer, 1976). Using this definition of "impulsive," a large segment of the population is being identified as having a maladaptive response style. Many studies have then attempted to modify this behavior based upon the individual's performance on this one test. In most of these studies there has been no attempt to assess whether or not these children are, in fact, experiencing difficulty as a result of their operationally defined "problem."

Research is needed to establish normative data for the MFFT so that an individual's cognitive tempo will be based upon test performance independent of the community in which he/she happens to be 
attending school at the time he/she takes the test. The establishment of construct and concurrent validity is also needed. How well does MFFT impulsivity correlate with clinical judgments, teacher ratings, and other measures of impulsivity? Is MFFT impulsivity predictive of learning difficulties? Multiple regression techniques are well-suited to research of this type since the variables are continuous and the purpose is prediction.

Sample Selection

If further attempts to modify impulsive behavior are attempted, vartous steps should be taken to insure that: (1) the children are indeed impulsive; and (2) the impulsivity is maladaptive--i.e., that it is interfering with the child's ability to experience success. The latter can be insured by seeking recommendations from teachers of children whom they perceive as having learning difficulties, or by utilizing special education populations. Groups categorized as learning disabled, neurologically impaired, and emotionally disturbed are likely to contain large numbers of impulsive children.

\section{Practical Implications}

One unanticipated outcome of this research was the development of a viable procedure for conducting research of this type in naturalistic settings. The university provides a potentially rich source of "experimenters." The undergraduate students who participated in this study profited greatly from the experience. The following quotes, taken from the tutors' logs, provide a representative sample of their feelings about the project: 
I feel I learned a lot tutoring the children. . . I would like to go into the field of special education and this course has helped me to plan lesson strategies and has offered me a chance for much needed practice working in a classroom setting with children.

This field experience should be opened to many people who are unsure of their field because it gives one a difderent perspective into the subject.

I learned a great deal from working with these kids-I learned that I do want to work on a one-to-one bas is with children. For many years I was unsure as to whether my interest lies in teaching or in working with learning disabled kinds. I think I finally found my answer. I know that this sounds really corny, but it is true.

I feel that this was quite an experience for me. I am an education major, and this was the first time I had done any work with children, other than observing. . . I was given the opportunity to work on a one-to-one basis with children who really needed a little extra attention.

Most of these students were juniors and seniors who are planning to work with children after they graduate. Nevertheless, most of them had never before been given the opportunity to apply the theories and skills that they have been taught in the university classroom. If experiences such as this were made available to students before they were required to "lock into" a major field, perhaps we would have fewer certified teachers and greater numbers of dedicated educators.

As the situation now exists, we have large numbers of enthusiastic college students who are thirsty for an opportunity to work with "real" children, large numbers of youngsters in need of extra help, and researchers looking for subject populations. It is possible to bring these groups together, at no real financial cost, and satisfy needs on all sides. As in the present case, this experience can be offered as a practicum, satisfying field work and/or elective requirements. 
The course could be offered on a one-semester basis, but a year-long commitment is suggested if the purpose of the research is to evaluate a particular treatment method. Within any given semester, a significant amount of time is lost due to varying school system and university calendars. The therapeutic aspects of the relationship between tutor and child is a very important one, and one that should be permitted to develop over an extended period of time. Feedback from tutors and teachers indicated that the children looked forward to their tutorial sessions and responded very favorably to the support and attention that this relationship provided. The tutors were similarly affected, as illustrated by one tutor's comment:

I definitely grew close to these children as a result of this experience. They are people I won't soon forget.

Graduate students in Education and Psychology could receive credit for acting as supervisors and discussion leaders for the tutors. Each supervisor could also function as a liason between tutors/university and teachers/school system. They could lead discussion groups for teachers and other school department personnel. These sessions could focus on the applications of the particular training method or treatment within the classroom, and ways in which the teachers can support the treatment being evaluated. This is an essential feature that was omitted in the present project due to the nature of the research design (i.e. to control for teacher expectancies). Similar groups could be held for parents, discussing ways in which they can help their children within the home environment. 


\section{Epilogue}

The needs and interests of researchers and clinicians/educators often appear to be at variance. The former are seeking answers to theoretical questions, while the latter may be more interested in providing a treatment program for individuals who are presently in need of such services and cannot wait for the definitive studies. These goals need not be mutually exclusive, provided that each group is willing to consider and incorporate into its own behavioral repertoire approaches of the other in order to establish greater common ground. Thus, researchers might address problems of concern to clinicians/ educators and conduct their research in naturalistic and field settings, while clinicians/educators might place greater emphas is on data collection, record keeping, and statistical analysis. An expansion of the traditional definition of "good experimental design" need not result in shoddy research, but rather, an increase in the options and flexibility available to both groups. The present study represents one attempt to bridge this gap between research and practice in the field of psychology. As in the present case, the research may not provide definitive answers to the questions it was designed to address; however, the heuristic value of the study will, hopefully, represent a substantial contribution to the field. 
APPENDIXES 


\section{APPENDIX A}

STOP, LISTEN, LOOK AND THINK CARD 


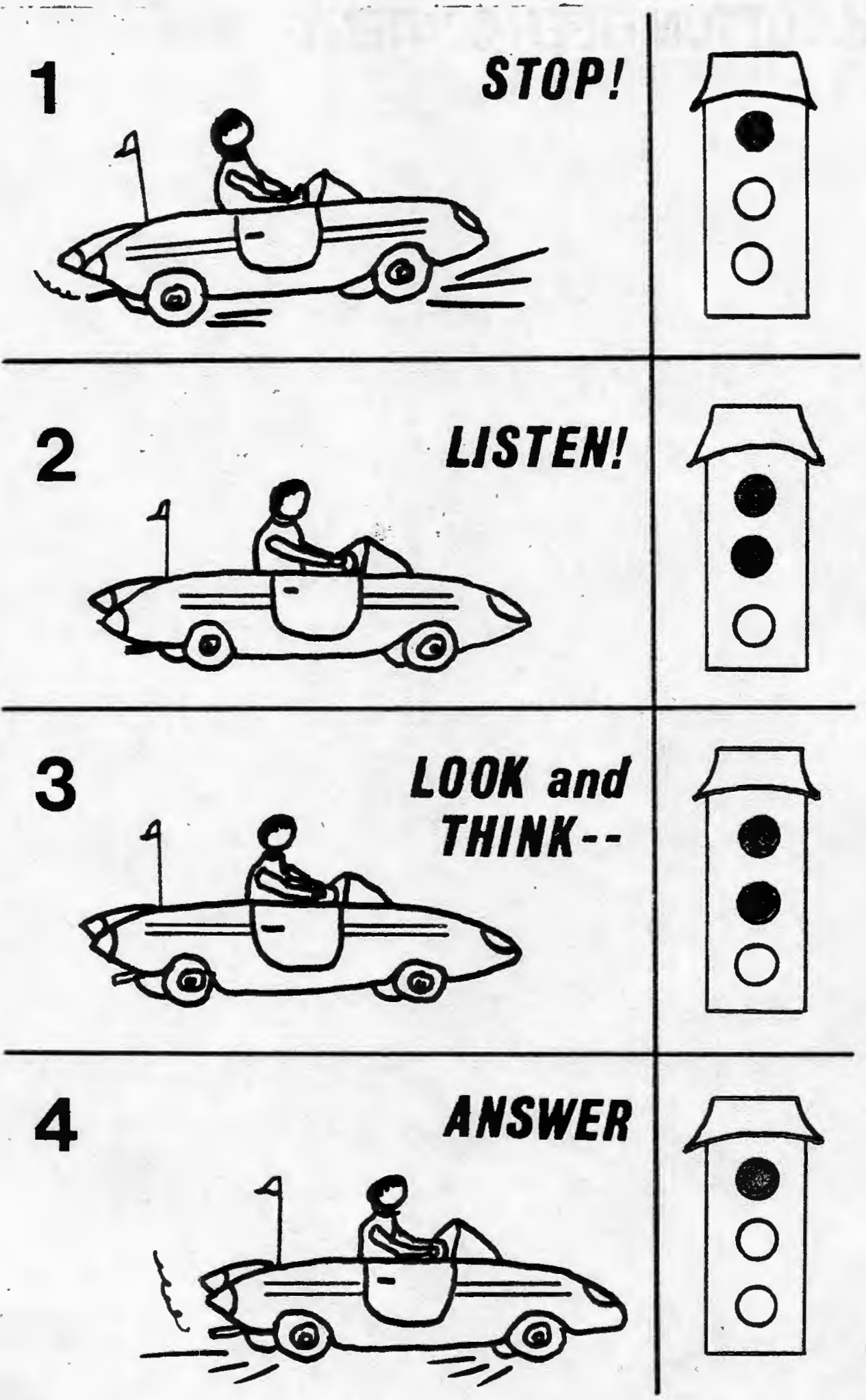

Designed by Barbara Van West 
APPENDIX B

INSTRUCTIONS FOR VSI TRAINING 
Remember when some teachers like myself came and had you find the picture that was the same as the other one? (Give as much explanation as necessary to help him remember the MFFT.) Well, we wanted to learn about how you work. We found out that you sometimes work very quickly, and sometimes get an answer wrong that you could have gotten right. Is that true? Do you sometimes answer so quickly that you make a mistake?

I'm here to help you become a better worker. Would you like that? Your parents want you to have this extra help and have given their permission to have you do this. Each week on days we are going to work together, doing different kinds of assignments. (Check to see where the child is "at"--Does he have any questions? . . any fears or misconceptions about what this is about?)

I'm not going to mark the papers that we do together, and I'm not going to give them to your teacher. I just want to show you some new ways to work. This new way is called: "STOP - LISTEN - LOOK \& THINK." (Show the cue card.) See, we're going to use this card to help remind you of what you are supposed to do. (Explain card.)

\section{Academic Group}

Here's a reading paper. Let's pretend that I'm you and (teacher's name) has just handed out this paper. I'm going to think out loud while I do it to make sure that I don't forget anything. I want you to watch what I do and then I want you to try to do it the same way.

0.K. My teacher has just given me this assignment. What is it that I have to do? First, I will STOP, like it says here (refer to cue card) and LISTEN carefully to the directions that my teacher is giving. (Pretend to be listening.) Oh, it's a reading paper. (teacher's name) said to read the sample sentence first and circle the word that belongs in the sentence. Let me LOOK (point to work look on card). Here is the word "sample," so this must be the one. (Read from paper.) "We saw a happy boy and a sad girl. The girl was ... crying ... flying ... purple... asleep" Hmmm ... I'd better check the sentence again. (Re-read sentence) She was sad so she could be crying; no, she wouldn't be flying. . . that doesn't make any sense . . purple? no, that's silly. . asleep? no. The answer must be "crying" so I'll circle that word. Now, let's see: The girl was crying but the boy was... sick? laughing? hurt? angry? I'd better THINK (point to card)... It said the boy was happy so he probably wasn't sick. He could have been laughing. He wouldn't be happy if he was hurt or angry, so I'li pick laughing and circle that word on the paper. 
(Teacher's name) said to go ahead and to the rest of them. (Do several more. Then have the child do if from the beginning. He may feel embarrassed. Encourage him to do it; make it like a game. He doesn't have to be as detailed as you were, but make certain that he verbalizes each main step. Try to get him to incorporate the STOP LISTEN - LOOK \& THINK ruTes as he works.)

\section{Non-Academic Group}

Here's a copying assignment. Let's pretend that I' $m$ you and (teacher's name) has just given out this assignment. I'm going to think out loud while I do it to make sure that I don't forget anything. I want you to watch what I do and then I want you to try to do it the same way.

0.K. My teacher has just given me this booklet. What is it that I have to do? First, I will STOP, like it says here (refer to card) and LISTEN carefully to the directions that my teacher is giving. (Pretend to be listening.) Oh, it's a copying assignment. (Teacher's name) said to open the booklet from the back. (Do so) Now I have to LOOK, like it says on this card. Here's number 1. I have to copy each design in the box below it. The first one is a line that goes up and down. I will THINK before I do it, like it says here (refer to card), and then I go ahead and make one like it. (Draw line.) Here's another straight line. I STOP, LOOK, THINK, and then I go ahead. (Draw another vertical line.) Uh-oh! I made a mistake. I'll erase it carefully. This line goes this way (point to horizontal line). I'll do it right this time.

(Do several more. Then have the child do it from the beginning. He may feel embarrassed. Encourage him to do it; make it like a game. He doesn't have to be as explicit as you were, but make certain that he does verbalize each step. Try to get him to incorporate the STOP LISTEN - LOOK \& THINK rules as he works.) 
APPENDIX C

PRE- AND POSTTEST SCORES FOR

INDIVIDUAL SUBJECTS 
TABLE 7

PRE- AND POSTTEST SCORES FOR INDIVIDUAL SUBJECTS

Group Latency Error Pupil Rating Achievement Subject Pre Post Pre Post Pre Post Pre Post

\begin{tabular}{lrrrrrrrrr}
\hline VSI-A & 1 & 14.8 & 22.8 & 12 & 6 & 50 & 63 & 69 & 70 \\
& 2 & 8.9 & 9.0 & 15 & 4 & 59 & 71 & 65 & 68 \\
& 3 & 11.0 & 14.3 & 9 & 4 & 66 & 75 & 84 & 63 \\
& 4 & 9.8 & 6.8 & 16 & 17 & 58 & 70 & 83 & 79 \\
& 5 & 7.0 & 14.4 & 16 & 9 & 53 & 70 & 71 & 58 \\
& 6 & 14.3 & 23.1 & 6 & 5 & 64 & -- & 65 & 48 \\
& 7 & 11.5 & 8.5 & 18 & 5 & 60 & 63 & 45 & 36 \\
& 8 & 7.0 & 9.5 & 16 & 12 & 58 & -- & 37 & 47 \\
& 9 & 9.8 & 20.7 & 11 & 7 & 49 & -- & 20 & 16 \\
& 10 & 9.5 & 4.0 & 27 & 13 & 43 & 47 & 18 & 22 \\
& 11 & 6.8 & 22.9 & 15 & 5 & 66 & 79 & 38 & 46 \\
& 12 & 4.4 & 37.9 & 13 & 3 & 61 & -- & 74 & 84 \\
& 13 & 7.1 & 7.8 & 17 & 5 & 64 & -- & 74 & 85 \\
& 14 & 11.6 & 26.5 & 8 & 14 & 65 & 59 & 85 & 95 \\
& 15 & 8.8 & 16.3 & 18 & 11 & 46 & 65 & 33 & 59 \\
& 16 & 16.3 & 26.8 & 7 & 8 & 42 & 56 & 39 & 33 \\
17 & 10.2 & 18.3 & 8 & 4 & 59 & 56 & 86 & 86 \\
& 18 & 7.3 & 17.4 & 5 & 5 & 62 & -- & 91 & 86 \\
19 & 16.3 & 14.7 & 11 & 7 & 67 & 75 & 97 & 92
\end{tabular}

$\begin{array}{rrrrrrrrrr}\text { VSI-NA } & 1 & 4.9 & 7.8 & 23 & 11 & 61 & 63 & 63 & 71 \\ & 2 & 13.4 & 18.4 & 8 & 4 & 61 & 60 & 54 & 69 \\ & 3 & 7.8 & 9.3 & 5 & 9 & 53 & -- & 78 & 90 \\ & 4 & 5.8 & 7.0 & 16 & 14 & 54 & 53 & 35 & 33 \\ & 5 & 15.3 & 11.8 & 4 & 1 & 59 & 73 & 81 & 60 \\ & 6 & 14.7 & 5.4 & 10 & 6 & 48 & -- & 17 & 22 \\ & 7 & 6.1 & 9.3 & 21 & 6 & 55 & 64 & 22 & 34 \\ & 8 & 9.5 & 9.3 & 12 & 8 & 51 & 68 & 55 & 46 \\ & 9 & 5.0 & 15.0 & 20 & 8 & 47 & 67 & 31 & 56 \\ & 10 & 16.0 & 14.5 & 10 & 19 & 44 & 58 & 25 & 38 \\ & 17 & 9.4 & 16.8 & 11 & 8 & 60 & -- & 62 & 60 \\ & 12 & 5.8 & 22.3 & 10 & 13 & 53 & 56 & 53 & 56 \\ & 13 & 6.1 & 18.8 & 11 & 4 & 54 & 54 & 44 & 57 \\ & 14 & 14.6 & 16.2 & 11 & 5 & 56 & 59 & 64 & 74 \\ & 15 & 15.8 & 22.1 & 8 & 7 & 53 & 63 & 38 & 39 \\ & 16 & 8.8 & 16.1 & 9 & 3 & 49 & -- & 56 & 55 \\ & 17 & 8.8 & 17.2 & 10 & 6 & 58 & 59 & 88 & 72 \\ & 18 & 7.8 & 26.5 & 15 & 6 & 49 & 50 & 65 & 64 \\ & 19 & 7.8 & 18.4 & 8 & 4 & 63 & -- & 76 & 74\end{array}$


TABLE 7-Continued

Group Subject Pre Post Pre Prror Post Pre Post Pre Post

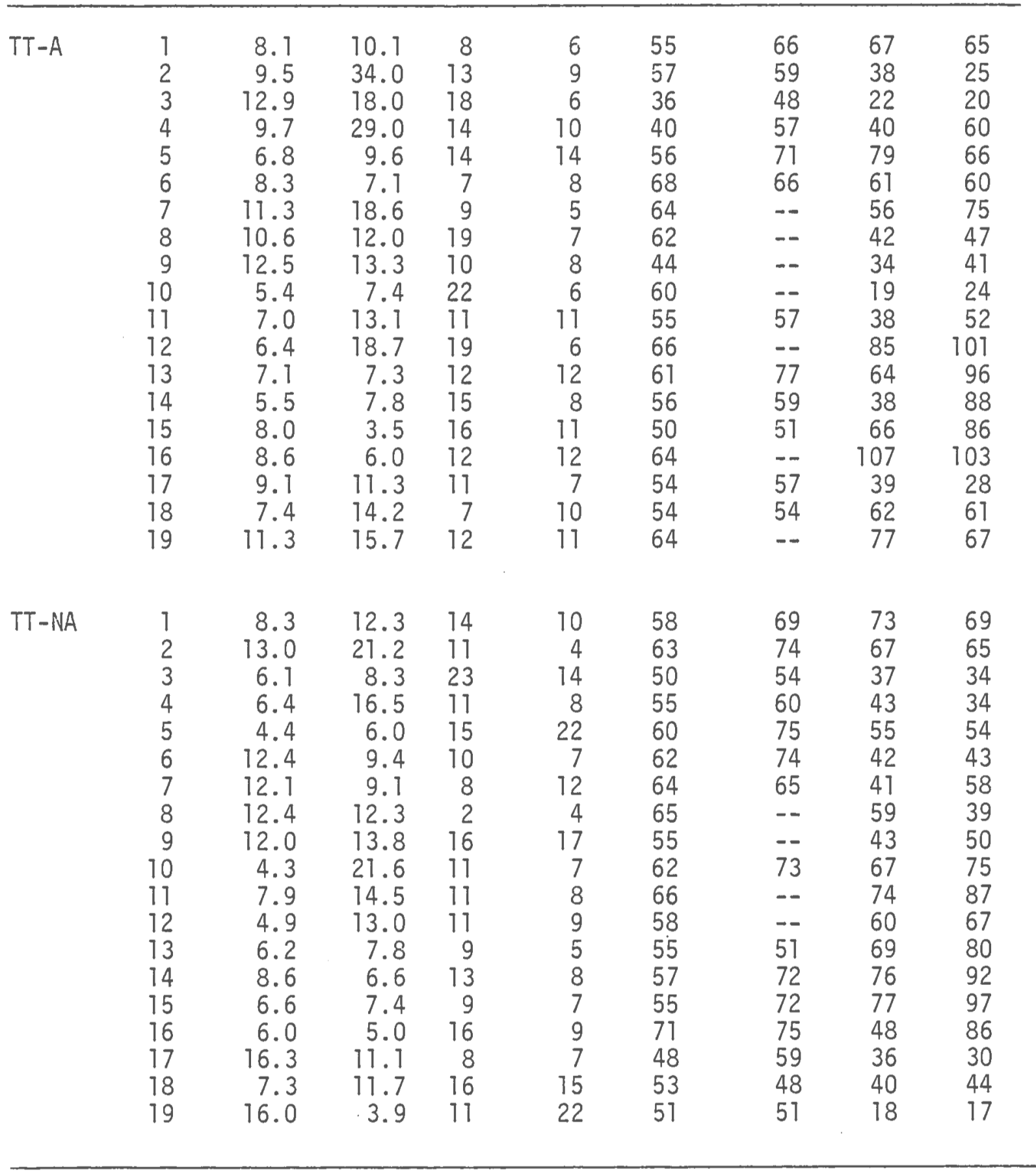




\section{REFERENCES}

Bandura, A., \& Walters, R. Social Learning Theory and Personality Development. New York: Holt, Rinehart \& Winston, 1963.

Barabash, C. A comparison of self instruction training, token fading procedures, and a combined self instruction-token fading treatment in modifying children's impulsive behaviors. Unpublished Doctoral dissertation, New York University, 1978.

Beery, K. E., \& Buktenica, N. A. Developmental Test of Visual-Motor Integration. Chicago: Follett Publishing Co., 1967.

Bender, N. Self-verbalization versus tutor verbalization in modifying impulsivity. Journal of Educational Psychology, 1976, 68, 347354.

Briggs, C. H. An experimental study of reflection-impulsivity in children. Dissertation Abstracts International, 1968, 28, 3891B92B.

Briggs, C., \& Weinberg, R. Effects of reinforcement in training children's conceptual tempo. Journal of Educational Psychology, 1973, $65,383-394$.

Campbe11, S., Douglas, V., \& Morgenstern, G. Cognitive styles in hyperactive children and the effect of methylphenidate. Journal of Child Psychology and Psychiatry, 1971, 12, 55-67.

Cathcart, G., \& Liedtke, W. Reflectiveness/impulsiveness and mathematics achievement. The Arithmetic Teacher, 1969, 563-567.

Clements, S. Minimal brain dysfunction in children. NINDB Monograph \#3 (USPHS Publication \#1475). Washington, D.C.: U.S. Department of Health, Education and Welfare, 1966.

Cohen, S., \& Przybycien, C. Some effects of sociometrically selected peer models on the cognitive styles of impulsive children. The Journal of Genetic Psychology, 1974, 124, 213-220.

Debus, R. Effects of brief observation of model behavior on conceptual tempo in impulsive children. Developmental Psychology, 1970, 2., $22-32$. 
Denney, D. Modeling effects upon conceptual style and cognitive tempo. Child Development, 1972, 43, 105-119.

Denney, D. Reflection and impulsivity as determinants of conceptual strategy. Child Development, 1973, 44, 614-623.

Douglas, V. Stop, look and listen: The problem of sustained attention and impulse control in hyperactive and normal children. Canadian Journal of Behavioral Science, 1972, 4, 259-281.

Douglas, V. Sustained attention and impulse control: Implications for the handicapped child. In J. A. Swets and L. L. Elliott (Eds.) Psychology and the Handicapped Child. Washington, D.C.: U.S. Department of Health, Education and Wel fare, 1974.

Drabman, R. S., Spitalnik, R., \& O'Leary, K. D. Teaching self-control to disruptive children. Journal of Abnormal Psychology, 1973, $82,10-16$.

Drake, D. Perceptual correlates of impulsive and reflective behavior. Developmental Psychology, 1970, 2, 202-214.

Dykman, R. A., Ackerman, P. T., Clements, S. D., \& Peters, J. E. Specific learning disabilities: An attentional deficit syndrome. In H. R. Myklebust (Ed.), Progress in Learning Disabilities. Vol. 2, New York: Grune \& Stratton, 1971.

Egeland, B. Training impulsive children in the use of more efficient scanning techniques. Child Development, 1974, 45, 165-171.

Epstein, M., Hallahan, D., \& Kauffman, J. Implications of the reflectivity-impulsivity dimension for special education. Journal of Special Education, 1975, 9, 11-25.

Finch, A. J., Jr., Wilkinson, M. D., Nelson, W. M., III, \& Montgomery, L. E. Modification of an impulsive cognitive tempo in emotionaliy disturbed boys. Journal of Abnomal Child Psychology, 1975, $\underline{3}$, 47-51.

Finney, B. J. The modification of conceptual tempo in disadvantaged boys. Dissertation Abstracts International, 1970, 30, 3782A.

Goodenough, D., \& Eagle, C. A modification of the embedded-figures test for use with young children. Journal of Genetic Psychology, 1973, 103, 67-74.

Grinspoon, L., \& Singer, S. Amphetamines in the treatment of hyperkinetic children. Harvard Educational Review, 1973, 43, 515565. 
Hallahan, D., Kauffman, J., \& Ball, D. Selective attention and cognitive tempo of low achieving and high achieving sixth grade males. Perceptual and Motor Ski71s, 1973, 36, 579-583.

Haring, N. G., \& Ridgway, R. W. Early identification of children with learning disabilities. Exceptional Children, 1967, 5, 387-395.

Heider, E. R. Information processing and the modification of an impulsive conceptual tempo. Child Development, 1971 , 42, 12761281 .

Jastak, J. F., \& Jastak, S. R. Wide Range Achievement Test. Wilmington, Delaware: Guidance As sociates of Delaware, Inc., 1965.

Kagan, J. Impulsive and reflective children: The significance of conceptual tempo. In J. D. Krumboltz (Ed.) Learning and the educational process. Chicago: Rand McNaliy, $\frac{1965,133-161 .}{1}$

Kagan, J. Reflection-impulsivity and reading ability in primary grade children. Child Development, 1965, 36, 609-628.

Kagan, J. Developmental studies in reflection and analysis. In A. Kidd \& J. Rivoire (Eds.), Perceptual development in children. New York: International Universities Press, 1966. (a)

Kagan, J. Reflection-Impulsivity: The generality and dynamics of conceptual tempo. Journal of Abnormal Psychology, 1966, 71, 17-24. (b)

Kagan, J. Pearson, L., \& Welch, L. Conceptual impulsivity and inductive reasoning. Child Development, 1966, 37, 583-594. (a)

Kagan, J., Pearson, L., \& Welch, L. The modifiability of an impulsive tempo. Journal of Educational Psychology, 1966, 57, 359-365.

Kagan, J., Rosman, B., Day, D., Albert, J., \& Phillips, W. Information processing in the child: Significance of analytic and reflective attitudes. Psychological Monographs, 1964, 78 (1, Whole No. 578).

Kelley, T., Madden, R., Gardner, E., \& Rudman, H. Stanford Achievement Test Primary II Battery. New York: Harcourt, Brace and WorTd, Inc., 1964.

Kenda11, P. C., \& Finch, A. J., Jr. A cognitive-behavioral treatment for impulse control: A case study. Journal of Consulting and Clinical Psychology, 1976, 44, 852-857.

Keogh, B. Hyperactivity and learning disorders: Review and speculation. Exceptional Child, 1971, 38, 101-110. 
Keogh, B., \& Donlon, G. Field dependence, impulsivity and learning disabilities. Journal of Learning Disabilities, 1972, 5 , 331336.

Keogh, B., \& Margolis, J. Learn to labor and to wait: Attentional problems of children with learning disorders. Journal of Learning Disabilities, 1976, 9 , 276-386.

Lerner, J. Children with learning disabilities. Boston: Houghton Mifflin Co., 1971.

Luria, A. The role of speech in the regulation of normal and abnormal behavior. New York: Liveright, 1961.

Madden, R., Gardner, E. F., Rudman, H. C., Karlsen, B., \& Merwin, . J. C. Stanford Achievement Test, Primary Level II, Form A. New York: Harcourt, Brace, Jovanovich, Inc., 1973.

Meichenbaum, D. Cognitive-behavior modification: An integrative approach. New York: PTenum Press, 1977.

Meichenbaum, D. Self-instructional methods. In F. Kanfer \& A. Goldstein (Eds.), Helping People Change. New York: Pergamon Press, 1975. (a)

Meichenbaum, D. Toward a cognitive theory of self-control. In G. Schwartz \& D. Shapiro (Eds.), Consciousness and Self-Reguiation: Advances in Research. New York: Plenum Press, 1975. (b)

Meichenbaum, D., \& Goodman, J. Reflection-impulsivity and verbal control of motor behavior. Child Development, 1969, 40, 785-797.

Meichenbaum, D., \& Goodman, J. Training impulsive children to talk to themseives: A means of developing self-control. Journal of Abnormal Psychology, 1971, 77, 115-126.

Messer, S. Reflection-impulsivity: A review. Psychological Bulletin, $1976,83,1026-1052$.

Myklebust, $H$. The Pupil Rating Scale: Screening for learning disabilities. New York: Grune \& Stratton, 1971.

Nelson, W. M., III, Finch, A. J., Jr., \& Hooke, J. F. Effects of reinforcement and response-cost on cognitive style in emotionally disturbed boys. Journal of Abnormal Psychology, 1975, 84, 426-428.

O'Leary, K. D., Becker, W. C., Evans, M. B. \& \& Saudargas, R. A. A token reinforcement program in a public school: A replication and systematic analys is. Journal of Applied Behavior Analys is, $1969,2,3-13$. 
O'Leary, K. D., \& Drabman, R. Token reinforcement programs in the classroom. Psychological Bulletin, 1971, 프, 379-398.

O'Leary, K. D., Drabman, R., \& Kass, R. E. Maintenance of appropriate behavior in a token program. Journal of Abnormal Child Psychology, 1973, I, 127-128.

Palkes, H., Stewart, M. , \& Kahana,B. Porteus maze performance of hyperactive boys after training in self-directed verbal commands. Child Development, 1968, 39, 817-829.

Raven, J. The coloured progressive matrices. London: H. K. Lewis \& Co., Ltd., 1962.

Ridberg, E., Parke, R., \& Hetherington, E. Modification of impulsive and reflective cognitive styles through observation of film-mediated models. Developmental Psychology, 1971, $5,369-377$.

Ross, A. Psychological aspects of learning disabilities and reading disorders. New York: McGraw-Hi17, 1976.

Routh, D., \& Roberts, R. Minimal brain dysfunction in children: Failure to find evidence for a behavioral syndrome. Psychological Reports, $1972,31,307-374$.

Siegel, A., Kirasic, K., \& Kilburg, R. Recognition memory in reflective and impulsive preschool children. Child Development, 1973, 44, $651-656$.

Spears, C. \& Weber, R. The nature of learning disabilities. In R. Weber (Ed.), Handbook on learning disabilities: A prognosis for the child, the adolescent, the adult. New Jersey Association for Children with Learning Disabilities, Englewood Cliffs, N.J.: Prentice-Ha11, Inc., 1974.

Sprague, R. L., Barnes, K. R., \& Werry, J. S. Methylphenidate and thioridazine: learning reaction time, activity, and classroom behaviour in emotionaliy disturbed children. American Journal of Orthopsychiatry, $1970,40,615$.

Tarver, S., \& Hallahan, D. Attention deficits in children with learning disabilities: A review. Journal of Learning, 1974, 7, 560-569.

Vygotsky, L. Thought and Language. New York: Wiley, 1962.

Wechsler, D. Manual for the Wechsler Intelligence Scale for ChildrenRevised. New York: Psychological Corporation, 1974.

Weiss, G., Kruger, E., Danielson, U., \& Elman, M. Effect of long-term treatment of hyperactive children with methylphenidate. Canadian Medical Association Journal, 1975, 112, 159-165. 
Wender, P. H. Minimal Brain Dysfunction in Children. New York: Wiley-Interscience, 1971 .

Winer, B. Statistical Principles in Experimental Design. New York: McGraw-Hi17, 1962.

Yando, R., \& Kagan, J. The effect of teacher tempo on the child. Child Development, 1968, 39, 27-34.

Zelniker, T., Jeffrey, W., Ault, R., \& Parsons, J. Analysis and modification of search strategies of impulsive and reflective children on the matching familiar figures test. Child Development, $1972,43,321-355$.

Zelniker, T., \& Oppenheimer, L. Modification of information processing of impulsive children. Child Development, 1973, 44, 445-450. 